\title{
Analysis of 31 Hydrazones of Carbonyl Compounds by RRLC-UV and RRLC-MS(/MS): A Comparison of Methods
}

\author{
Soraya de M. Ochs, ${ }^{1,2}$ Maíra Fasciotti, ${ }^{2}$ and Annibal D. Pereira Netto ${ }^{1,3}$ \\ ${ }^{1}$ Programa de Pós-Graduação em Química, Instituto de Química, Universidade Federal Fluminense, Outeiro de São João Batista, \\ $s / n$, Centro, 24020-141 Niterói, RJ, Brazil \\ ${ }^{2}$ Instituto Nacional de Metrologia, Qualidade e Tecnologia (INMETRO), Avenida Nossa Senhora das Graças 50, \\ 25250-200 Duque de Caxias, RJ, Brazil \\ ${ }^{3}$ Departamento de Química Analítica, Instituto de Química, Universidade Federal Fluminense, Outeiro de São João Batista, \\ s/n, Centro, 24020-141 Niterói, RJ, Brazil
}

Correspondence should be addressed to Maíra Fasciotti; mfasciotti@inmetro.gov.br and Annibal D. Pereira Netto; annibal@vm.uff.br

Received 31 October 2014; Accepted 15 December 2014

Academic Editor: Nives Galić

Copyright ( $) 2015$ Soraya de M. Ochs et al. This is an open access article distributed under the Creative Commons Attribution License, which permits unrestricted use, distribution, and reproduction in any medium, provided the original work is properly cited.

\begin{abstract}
Aldehydes and ketones are volatile organic compounds (VOC) emitted into the atmosphere by a large number of natural and anthropogenic sources. Carbonyl compounds (CC) are atmospheric pollutants with known damaging effects for the human's health. In this work, the separation of 31 carbonyl compounds (CC) in their 2,4-dinitrophenylhydrazones form was optimized by rapid resolution liquid chromatography in 9 minutes and simultaneously detected by ultraviolet and mass spectrometry with an $\mathrm{APCI}(-)$ as ionization source. The mass spectra of hydrazones presented the $[\mathrm{M}-\mathrm{H}]^{-}$ions as base peak, but the MS/MS spectra showed fragments related to different structural classes of aldehydes and ketones, representing an important tool to assist structure elucidation of unknown CC in real samples. Multiple reactions monitoring (MRM) improved the sensitivity and selectivity for the quantitation method. Analytical parameters using both UV and MS (linearity, determination coefficients, detection limits, and sensitivity) were compared. The detection methods are complementary and a powerful analytical tool for the detection and quantitation of CC in complex environmental samples.
\end{abstract}

\section{Introduction}

Aldehydes and ketones are volatile organic compounds (VOC) emitted to the atmosphere by a large number of natural and anthropogenic sources, such as vegetation and industrial emissions $[1,2]$, cigarette smoke $[3,4]$, and fossil fuel or vegetation burning $[5,6]$. VOC photooxidation is also considered a secondary source of the emission of these compounds [6]. Carbonyl compounds (CC) affect the atmospheric chemistry of polluted areas through a series of complex routes. The induction period for the generation of photochemical smog decreases significantly with increasing concentrations of CC, due to their high reactivity, resulting in increased ozone concentration in the troposphere [7]. Certain CC can also affect human health; for example, formaldehyde is classified as carcinogenic and acetaldehyde as probably carcinogenic by International Agency for Research on Cancer (IARC) [8, 9]. CC also occur in a large number of environmental and artificial matrixes such as natural and drinking waters and disinfected and swimming pool water. They can also be formed during the frying process of vegetable oil as byproducts of thermal degradation/oxidation $[1,10]$.

There is great interest to improve the detection limits of techniques for the CC determination at trace levels (ppb) for several important applications, for example, characterization of air emission from combustion process and industrial sources, air pollution, and evaluation of human exposure to toxic contaminants present in indoor and work place areas.

Many analytical techniques have been employed for the analysis of aldehydes and ketones in air as previously discussed [10], but certainly their derivatization using 
2,4-dinitrophenylhydrazine (DNPH) in acidic media to form the respective hydrazones followed by the analysis using high performance liquid chromatography and UV detection (HPLC-UV) at $360 \mathrm{~nm}$ has been the technique of choice for CC determination [10-15]. Moreover, this methodology is currently recommended by environmental agencies including the US Environmental Protection Agency (US EPA) [14].

Regarding the analytical tools for CC determinations, significant improvement of resolution, detectability, and analytical throughput is now being achieved by using LC stationary phases with sub- $2 \mu \mathrm{m}$ particles, well known as rapid resolution or ultraperformance liquid chromatography (RRLC or UPLC) [16]. In a recent work, we optimized the conditions of rapid resolution liquid chromatography (RRLC) for determination of hydrazones and compared them with those of HPLC-UV [10]. The RRLC method allowed the determination of up to 31 atmospheric CC [17] and the monitoring of occupational exposure to formaldehyde in an institute of morphology [18].

On the other hand, HPLC-MS allowed significant improvement in quantification and positive identification of a number of carbonyls in samples. Oehme and coworkers applied this technique to investigate the fragmentation pathways of some CC $[19,20]$. An ion trap mass spectrometer, following atmospheric pressure chemical ionization (APCI) and detection of negative ions, was applied for the evaluation of air samples [15, 21, 22]. This method was also applied in other works to determine CC, such as the evaluation of oxidation products formed in the reaction between pinene and $\mathrm{OH}$ radicals $[23,24]$, biological relevant aldehydes in exhaled breath [25], and carbonyl compounds in urine [26]. Electrospray ionization (ESI) $[12,26-28]$ or atmospheric pressure photoionization (APPI) $[29,30]$ was also implemented, but APCI is the most frequent ionization method used for CC detection and quantitation [15, 21, 22, 25, 31-33].

Herein, we describe the comparison of the two methods of detection of the DNPH derivatives (hydrazones) of 31 carbonyl compounds. For this purpose, sequential detection of the hydrazones using both UV and negative mode APCIMS/MS was employed following their separation under previously optimized RRLC conditions. The choice of these chromatographic conditions and the sequential detection allowed simultaneous detection of all hydrazones in the same optimized separation conditions.

\section{Materials and Methods}

2.1. Reagents and Solvents. A standard solution containing 15 CC-DNPH derivatives (hydrazones of formaldehyde, acetaldehyde, acetone, acrolein, propionaldehyde, crotonaldehyde, butyraldehyde, benzaldehyde, isovaleraldehyde, valeraldehyde, o-, m-, and p-tolualdehydes, hexaldehyde, and 2,5-dimethylbenzaldehyde) in concentrations corresponding to $15 \mathrm{mg} \cdot \mathrm{L}^{-1}$ of each carbonyl compounds was purchased from Sigma (T011/IP-6A Aldehyde/Ketone-DNPH mix; Supelco). Other 16 hydrazones of selected CC (specifically, 2,3-butanedione, butanone, methacrolein, salicylaldehyde, cyclohexanone, 3-pentanone, 2-pentanone, p-methoxyacetophenone, methyl isobutyl ketone, heptanaldehyde, octylaldehyde, nonanaldehyde, decanaldehyde, undecanaldehyde, dodecanaldehyde, and tridecanaldehyde) were synthesized via a reaction with DNPH (Aldrich) in sulfuric acid solution [34]. The solids were purified after two recrystallization steps in ethanol. The crystals were dried and used as DNPH standards, after evaluation of their purities by RRLC-UV.

Acetonitrile, methanol, tetrahydrofuran, and isopropanol (HPLC grade) were from Tedia, Brazil. Ultrapurified water was prepared through a Simplicity System (Millipore, EUA) following reversed osmosis (Rios D3, Millipore, EUA).

2.2. Standard Solutions. A standard stock solution of the 15 carbonyl-DNPH derivatives was prepared by dilution of $1.00 \mathrm{~mL}$ of the standard solution up to $3.00 \mathrm{~mL}$ using acetonitrile. Standard solutions of the 16 carbonyl-DNPH derivatives synthesized by our group were prepared by weighing appropriate masses of the synthesized solids and dissolving them in acetonitrile. Working standards were prepared by dilution of appropriate aliquots of the stock solution up to $1.00 \mathrm{~mL}$ using acetonitrile.

2.3. Chromatographic Separation and Detection. A rapid resolution liquid chromatography system (Agilent 1200 Series, USA) equipped with a binary pump, a degasser, an automated injector, a thermostated column compartment and an ultraviolet diode array detector (UV-DAD), and an Ion Trap SL mass spectrometer (IT-MS) (Agilent 6300 Series, USA) was used. The UV-DAD and IT-MS were connected in series through the output of the UV-DAD detector that was directly connected to the APCI source, operating in negative ion mode in the mass range of $m / z 50-500$.

A rapid separation (around $9.5 \mathrm{~min}$ in total) of the 31 hydrazones was achieved using a Zorbax Eclipse Plus C18 $(50 \times 2.1 \mathrm{~mm} ; 1.8 \mu \mathrm{m}$, Agilent, USA $)$ column and the previously optimized conditions [10]. Briefly, a quaternary mobile phase consisted of methanol, tetrahydrofuran (THF), isopropanol, and water. The best separation condition was obtained at $35^{\circ} \mathrm{C}$ of column temperature, using a multistep gradient of methanol (A) and a mixture of water $(75 \% \mathrm{v} / \mathrm{v})$, isopropanol $(15 \% \mathrm{v} / \mathrm{v})$, and THF $(10 \% \mathrm{v} / \mathrm{v})(\mathrm{B})$. The mobile phase gradient was as follows: $0-30 \%$ of (A) in $2 \mathrm{~min}$, held constant during $0.5 \mathrm{~min}$; a linear gradient to $80 \%$ of (A) during $2.5 \mathrm{~min}$; a linear gradient of $(\mathrm{A})$ to $85 \%$ during $1.5 \mathrm{~min}$, held constant during $3 \mathrm{~min}$. The flow rate was $0.55 \mathrm{~mL} \mathrm{~min}^{-1}$ which is compatible with the APCI characteristics. Volumes of $3 \mu \mathrm{L}$ were injected and an equilibration time of $1 \mathrm{~min}$ between successive RRLC runs was always adopted. Prior to use, all solvents were filtered using polyvinylidene fluoride membrane filters $(0.22 \mu \mathrm{m}, 47 \mathrm{~mm}$, Millipore).

Parameters of the UV-DAD detector such as detector slit and response time that directly influence the detector signals were further optimized. A slit of $4 \mathrm{~nm}$ and a response time of 0.05 min gave the best responses considering peak width and form and chromatogram smooth [10]. Detection was carried out at $360 \mathrm{~nm}$.

The mass spectrometer was calibrated by direct infusion of the Tune Mix Solution (APCI/APPI Calibrant Solution, 
G2432A, Agilent) at a constant flow rate of $0.60 \mathrm{~mL} \mathrm{~h}^{-1}$, using an automated syringe pump in APCI(-). For quantitative evaluations, the Expert Parameters Settings were used and MS parameters were optimized to improve the detection of the ion $\mathrm{m} / \mathrm{z} 556$ of the calibrant solution continuously injected by the automated syringe pump.

Parameters of ionization and of the APCI interface were optimized by carrying out multiple injection of a standard mixture of hydrazones while each parameter was varied to obtain the best signal-to-noise ratio for hydrazones mass spectra.

2.4. Carbonyl-DNPH Derivatives Identification and Quantification. All hydrazones were first detected by their retention time and elution order, considering their detection by the UV-DAD detector [10].

In order to evaluate the detection limits (DL) and quantification limits (QL) of each hydrazone, calibration curves were built between the range of 1.00 and $500 \mu \mathrm{g} \mathrm{L}-1$ with standard solutions containing all the studied hydrazones. Calibration curves were then obtained by least-squares regression of data. In this way, DL and QL were obtained by the ratio between three and ten times the signal-to-noise ratio by the angular coefficients of calibration curves, for DL and QL, respectively. Signal-to-noise ratios were estimated by standard deviations of peak areas obtained after 6 subsequent injections of the most diluted standards $(1.00,2.00$, and $5.00 \mu \mathrm{g} \mathrm{L}^{-1}$ ) [35].

\section{Results and Discussion}

3.1. Optimization of MS Conditions. Instrumental parameters of the mass spectrometer were optimized by direct infusion of the calibrant solution and detection of the ion $\mathrm{m} / z 556$ in negative mode. These parameters were used in all MS evaluations (Table 1).

Parameters for the acquisition of mass spectra data were optimized by carrying out multiple injections $(3 \mu \mathrm{L})$ of a solution obtained after dilution of the Supelco hydrazones mixture to a final concentration of $50.00 \mu \mathrm{g} \mathrm{L}^{-1}$. Each APCI source parameter was varied in order to obtain the best signal-to-noise ratio for the deprotonated molecules, $[\mathrm{M}-\mathrm{H}]^{-}$ ions (Figure 1).

Ionization processes in the APCI interface occur in vapor phase and are strongly influenced by the vaporization temperature of the nebulizer and by the drying temperature of the source. Vaporization temperature of the APCI source was evaluated between the range of 150 and $400^{\circ} \mathrm{C}$ under the optimized chromatographic conditions, leading to an optimal condition at $400^{\circ} \mathrm{C}$. The best APCI drying temperature was also optimized and found to be at $350^{\circ} \mathrm{C}$. A nitrogen flow of $5 \mathrm{~L} \mathrm{~min}^{-1}$ is suggested for the RRLC flow rate $\left(0.55 \mathrm{~mL} \mathrm{~min}^{-1}\right)$ and the default nebulizer gas pressure of $60 \mathrm{psi}$ was used. Values for all the optimized APCI parameters are shown in Table 2.

3.2. Evaluation of MS/MS Spectra of Carbonyl-DNPH Derivatives. The mass spectrum of 31 hydrazones obtained in
TABLE 1: Optimized mass spectrometry parameters for the detection of hydrazones.

\begin{tabular}{lc}
\hline Parameter & Optimized value \\
\hline Capillary (V) & 1,000 \\
Skimmer (V) & -33.1 \\
Capillary outlet (V) & -107.4 \\
Octupole 1 DC (V) & -4.4 \\
Octupole 2 DC (V) & -1.37 \\
Trap drive (V) & 40.03 \\
Octupole RF (V) & 136 \\
Lens 1 (V) & 0.82 \\
Lens 2 (V) & 33.6 \\
Trap drive & 30 \\
Target & 30,000 \\
\hline
\end{tabular}

APCI(-) is dominated mainly by its deprotonated molecules, $[\mathrm{M}-\mathrm{H}]^{-}$as base peak and the MS/MS spectra hydrazones of carbonyl compounds showed fragments related to different structural classes of aldehydes and ketones, represented in Figure 2.

Specific fragmentation pathways were observed as a function of the hydrazone structure. The fragment ions of MS/MS spectra obtained for different structures and their relative abundance are summarized in Table 3 . As previously shown $[19,21,31]$, the observed fragments of the hydrazones are related to different structural classes of aldehydes and ketones. For example, aliphatic aldehydes, such as propionaldehyde and heptanaldehyde, showed a relatively abundant ion of $\mathrm{m} / z 163(100 \%)$ and another of $\mathrm{m} / z 152$ with a relative abundance around 50\% (Figures 3(a) and 3(b)).

The MS/MS spectra of aromatic aldehydes showed characteristic fragment ion $[\mathrm{M}-\mathrm{H}-164]^{-}$with a relative abundance of around 50\%. It corresponded to an ion of $\mathrm{m} / z 121$ (Figure 3(d)) in the MS/MS spectra of benzaldehyde and to an ion of $m / z 135$ (Figure 3(c)) in the MS/MS spectra $\mathrm{o}^{-}, \mathrm{m}-$, and p-tolualdehydes-hydrazones, which coeluted under our chromatographic conditions [10]. Benzaldehyde and substituted aromatic aldehydes such as tolualdehydeshydrazones also exhibited the fragment ion $[\mathrm{M}-\mathrm{H}-93]^{-}$as observed in the MS/MS spectra $(\mathrm{m} / \mathrm{z}$ of 192 for benzaldehyde and $m / z 206$ for tolualdehydes, Figures 3(c) and 3(d)).

The MS/MS spectra of unsaturated aldehydes showed the fragment ion $[\mathrm{M}-\mathrm{H}-47]^{-}$due to the loss of $\mathrm{HNO}_{2}$ after ionization. For example, the MS/MS spectra of crotonaldehyde showed the fragment of $m / z 202$, with an approximate relative abundance of $40 \%$ (Figure 3(e)). This ion also showed a similar abundance in the MS/MS spectra of aromatic aldehydes, as observed for isomers of tolualdehyde-DNPH $(m / z 252)$ and benzaldehyde-DNPH $(m / z 238)$.

Typical fragments of $\alpha, \beta$-unsaturated aldehydes corresponded to ions of $[\mathrm{M}-\mathrm{H}-31]^{-}$and $[\mathrm{M}-\mathrm{H}-17]^{-}$, this one due to a neutral loss of $\mathrm{NH}_{3}$ [19]. These fragments were also observed in the MS/MS spectrum of crotonaldehyde-DNPH $(\mathrm{m} / z 218$ and 232, resp.). Derivatives of $\alpha$-hydroxylatedand dicarbonyl-CC hydrazones showed MS/MS spectra and similar fragmentation profiles, which are characterized by 
TABLE 2: Evaluated parameters for optimum response of hydrazones derivatives by APCI/MS.

\begin{tabular}{lcc}
\hline Parameter & Evaluated range & Optimum condition \\
\hline Corona needle & $2,000-20,000 \mathrm{nA}$ & $10,000 \mathrm{nA}$ \\
Vaporization temperature & $150-400^{\circ} \mathrm{C}$ & $400^{\circ} \mathrm{C}$ \\
Drying temperature & $250-350^{\circ} \mathrm{C}$ & $350^{\circ} \mathrm{C}$ \\
Ion charge control & $50,000-130,000$ & 70,000 \\
Maximum accumulation time & $100-600 \mathrm{~ms}$ & $200 \mathrm{~ms}$ \\
\hline
\end{tabular}

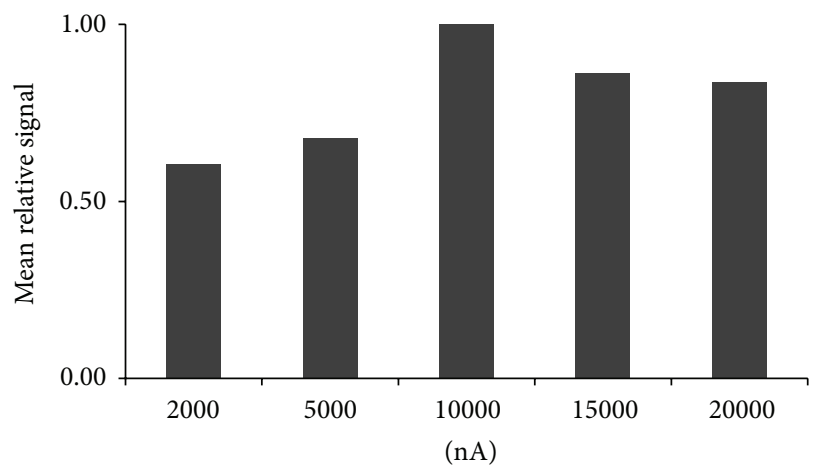

(a)

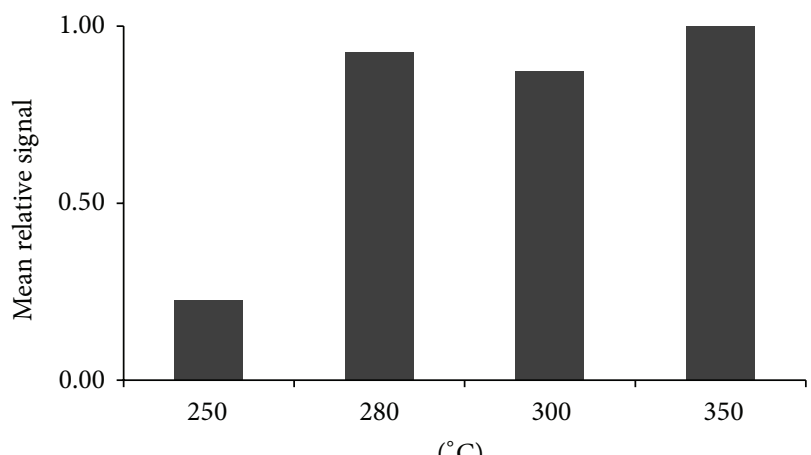

(c)

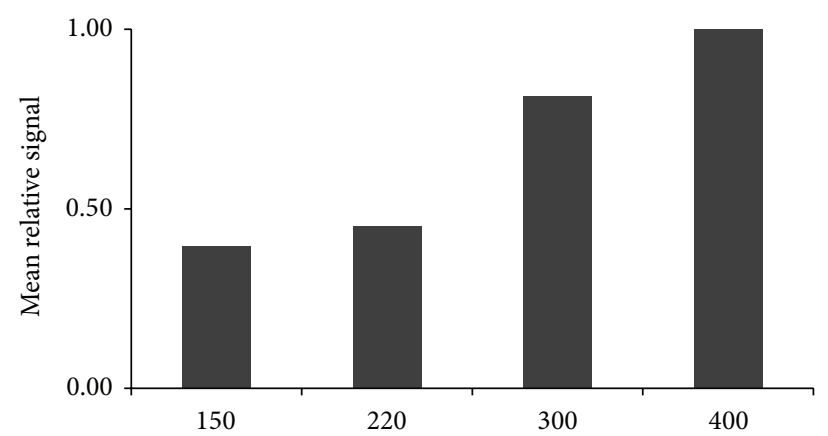

$\left({ }^{\circ} \mathrm{C}\right)$

(b)

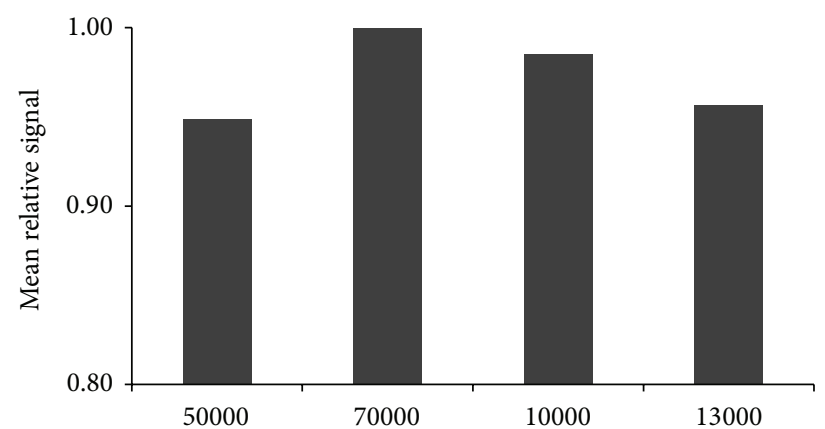

(d)

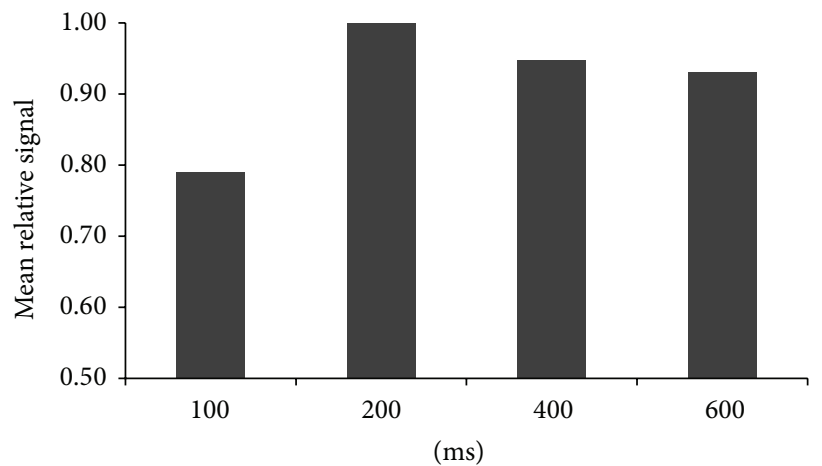

(e)

FIGURE 1: Evaluation of selected parameters for optimization of MS conditions by the average signal of CC derivatives: (a) corona needle $(\mathrm{nA})$; (b) vaporization temperature $\left({ }^{\circ} \mathrm{C}\right)$; (c) drying temperature $\left({ }^{\circ} \mathrm{C}\right)$; (d) ion charge control; and (e) maximum accumulation time (ms). 
TABLE 3: Major fragments $(\mathrm{m} / z)$ of $\mathrm{MS}^{2}$ spectrum formed by fragmentation of the precursor $[\mathrm{M}-\mathrm{H}]^{-}$ions of the hydrazones.

\begin{tabular}{|c|c|c|c|c|c|c|c|c|c|c|c|}
\hline \multirow{2}{*}{ Hydrazone } & \multirow{2}{*}[\mathrm{M}-\mathrm{H}]{$^{-}$} & \multicolumn{10}{|c|}{ Fragment ions of $[\mathrm{M}-\mathrm{H}]^{-}(m / z)$} \\
\hline & & 152 & 163 & 179 & 182 & {$[\mathrm{M}-\mathrm{H}-17]^{-}$} & {$[\mathrm{M}-\mathrm{H}-30]^{-}$} & {$[\mathrm{M}-\mathrm{H}-31]^{-}$} & {$[\mathrm{M}-\mathrm{H}-47]^{-}$} & {$[\mathrm{M}-\mathrm{H}-93]^{-}$} & {$[\mathrm{M}-\mathrm{H}-164]^{-}$} \\
\hline Formaldehyde & 209 & $\mathrm{xx}$ & $\mathbf{x x x}$ & $\mathrm{xx}$ & & & & & & & \\
\hline Acetaldehyde & 223 & $\mathrm{xx}$ & $\mathbf{x x x}$ & $\mathrm{xxx}$ & & & $\mathrm{X}$ & & & & \\
\hline 2,3-Butanedione & 265 & $\mathrm{xx}$ & & $\mathrm{xx}$ & & & $\mathrm{X}$ & & $\mathbf{x x x}$ & & \\
\hline Acetone & 237 & $\mathrm{xx}$ & & $\mathrm{xx}$ & & & $\mathrm{Xxx}$ & & $\mathrm{x}$ & & \\
\hline Acrolein & 235 & $\mathrm{x}$ & $\mathbf{x x x}$ & $\mathrm{xx}$ & & & $\mathrm{Xx}$ & & $\mathrm{xx}$ & & \\
\hline Propionaldehyde & 237 & $\mathrm{xx}$ & $\mathbf{x x x}$ & $\mathrm{xx}$ & & $\mathrm{x}$ & $\mathrm{Xx}$ & & $\mathrm{x}$ & & \\
\hline Crotonaldehyde & 249 & $\mathbf{x x x}$ & $\mathrm{xx}$ & $\mathrm{xx}$ & & $\mathrm{x}$ & & $\mathrm{xx}$ & $\mathrm{xx}$ & & \\
\hline Butanone & 251 & $\mathrm{xx}$ & & $\mathrm{xx}$ & & & $\mathbf{X x x}$ & & $\mathrm{x}$ & & \\
\hline Methacrolein & 249 & $\mathrm{xx}$ & $\mathbf{x x x}$ & $\mathrm{xx}$ & & $\mathrm{x}$ & & $\mathrm{x}$ & $\mathrm{xx}$ & & \\
\hline Butyraldehyde & 251 & $\mathrm{xx}$ & $\mathbf{x x x}$ & $\mathrm{xx}$ & & & $\mathrm{xx}$ & & $\mathrm{x}$ & & \\
\hline Salicylaldehyde & 301 & $\mathrm{x}$ & $\mathrm{xx}$ & & $\mathbf{x x x}$ & & & & $\mathrm{xx}$ & $\mathrm{x}$ & $\mathrm{Xx}$ \\
\hline Benzaldehyde & 285 & $\mathrm{x}$ & $\mathbf{x x x}$ & $\mathrm{x}$ & & & $\mathrm{x}$ & & $\mathrm{xx}$ & $\mathrm{x}$ & $\mathrm{Xx}$ \\
\hline Cyclohexanone & 277 & $\mathrm{x}$ & & $\mathrm{x}$ & & & $\mathbf{x x x}$ & & $\mathrm{x}$ & & \\
\hline 2- and 3-pentanone & 265 & $\mathrm{xx}$ & & $\mathrm{xx}$ & & & $\mathbf{x x x}$ & & $\mathrm{x}$ & & \\
\hline Isovaleraldehyde & 265 & $\mathrm{xx}$ & $\mathbf{x x x}$ & $\mathrm{xx}$ & & & $\mathrm{xx}$ & & $\mathrm{x}$ & & $\mathrm{x}$ \\
\hline Valeraldehyde & 265 & $\mathrm{xx}$ & $\mathbf{x x x}$ & $\mathrm{xx}$ & & & $\mathrm{xx}$ & & $\mathrm{x}$ & & $\mathrm{x}$ \\
\hline p-Methoxyacetophenone & 329 & $\mathrm{x}$ & & $\mathrm{x}$ & & & & & $\mathbf{x x x}$ & & $\mathrm{x}$ \\
\hline o-, m-, and p-tolualdehydes & 299 & $\mathrm{x}$ & $\mathbf{x x x}$ & $\mathrm{xx}$ & & & & & $\mathrm{xxx}$ & $\mathrm{x}$ & $\mathrm{xx}$ \\
\hline Methyl isobutyl ketone & 279 & $\mathrm{xx}$ & & $\mathrm{x}$ & & $\mathrm{x}$ & $\mathbf{x x x}$ & & $\mathrm{x}$ & & \\
\hline Hexaldehyde & 279 & $\mathrm{xx}$ & $\mathbf{x x x}$ & $\mathrm{xx}$ & & & $\mathrm{x}$ & & $\mathrm{x}$ & & $\mathrm{x}$ \\
\hline Dimethylbenzaldehyde & 313 & & $\mathrm{xx}$ & $\mathrm{x}$ & & & & & $\mathbf{x x x}$ & $\mathrm{x}$ & $\mathrm{xx}$ \\
\hline Heptanaldehyde & 293 & $\mathrm{xx}$ & $\mathbf{x x x}$ & $\mathrm{xx}$ & & $\mathrm{x}$ & $\mathrm{xx}$ & & $\mathrm{xx}$ & & $\mathrm{x}$ \\
\hline Octanaldehyde & 307 & $\mathrm{xx}$ & $\mathbf{x x x}$ & $\mathrm{xx}$ & & & $\mathrm{x}$ & & $\mathrm{x}$ & & $\mathrm{x}$ \\
\hline Nonanaldehyde & 321 & $\mathrm{xx}$ & $\mathbf{x x x}$ & $\mathrm{xx}$ & & & $\mathrm{xx}$ & & $\mathrm{xx}$ & & $\mathrm{x}$ \\
\hline Decanaldehyde & 335 & $\mathrm{xx}$ & $\mathbf{x x x}$ & $\mathrm{xx}$ & & $\mathrm{x}$ & $\mathrm{xx}$ & & $\mathrm{xx}$ & & $\mathrm{xx}$ \\
\hline Undecanaldehyde & 349 & $\mathrm{xx}$ & $\mathbf{x x x}$ & $\mathrm{xx}$ & & & $\mathrm{xx}$ & & $\mathrm{xx}$ & $\mathrm{x}$ & $\mathrm{xx}$ \\
\hline Dodecanaldehyde & 363 & $\mathrm{xx}$ & $\mathbf{x x x}$ & $\mathrm{xx}$ & & & $\mathrm{xx}$ & & $\mathrm{xx}$ & & $\mathrm{xx}$ \\
\hline Tridecanaldehyde & 377 & $\mathrm{xx}$ & $\mathbf{x x x}$ & $\mathrm{x}$ & & & $\mathrm{xx}$ & & $\mathrm{xxx}$ & $\mathrm{x}$ & $\mathrm{xxx}$ \\
\hline
\end{tabular}

Relative abundance: xxx: 100\%; xx: 50\%; $x: \leq 20 \%$.

$\mathbf{x x x}$ : fragment ion selected for SRM.

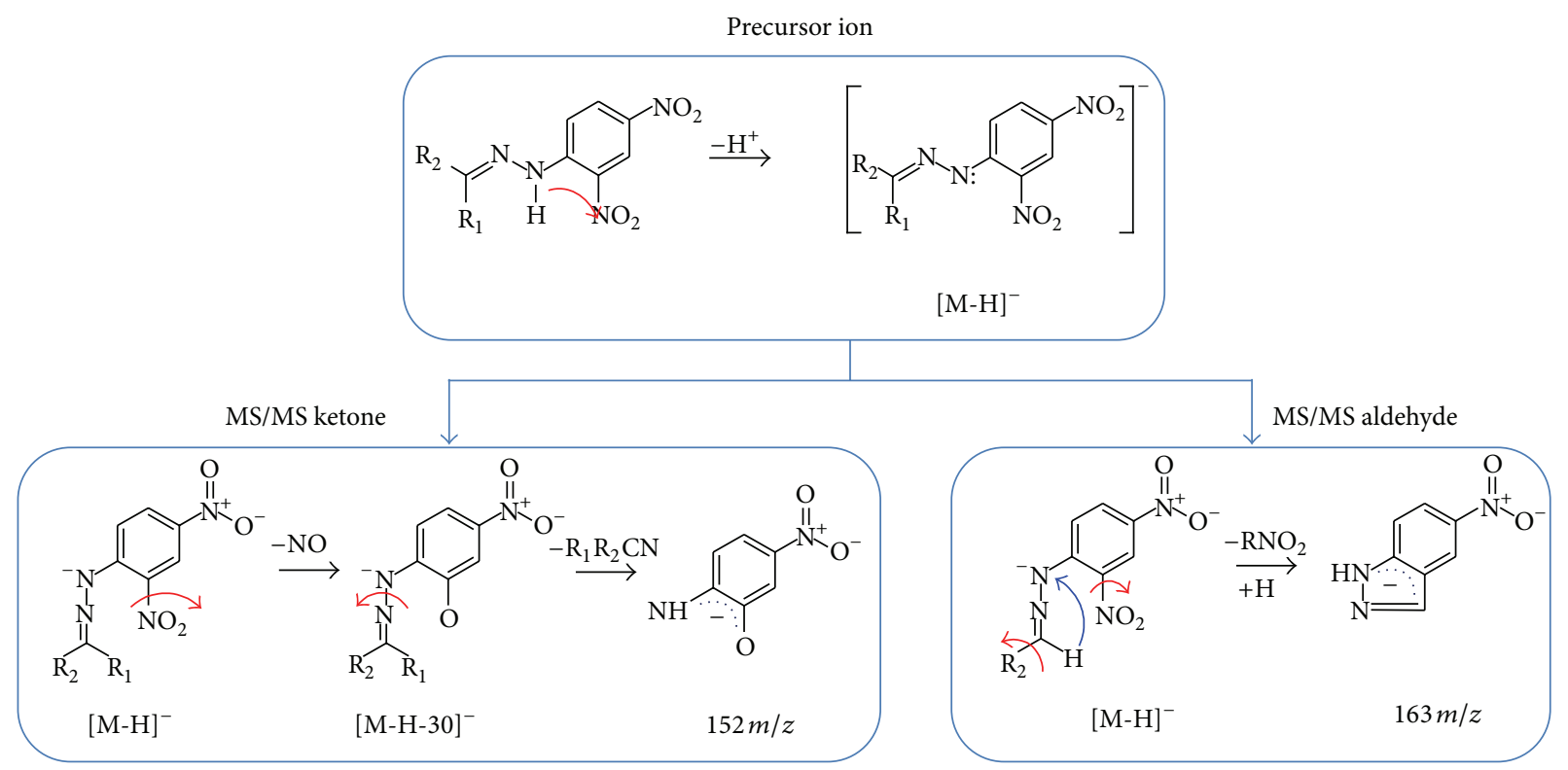

FIGURE 2: Schematic representation of the precursor deprotonated molecule $\left([\mathrm{M}-\mathrm{H}]^{-}\right)$and main fragments formations for aldehydes and ketones hydrazones. 


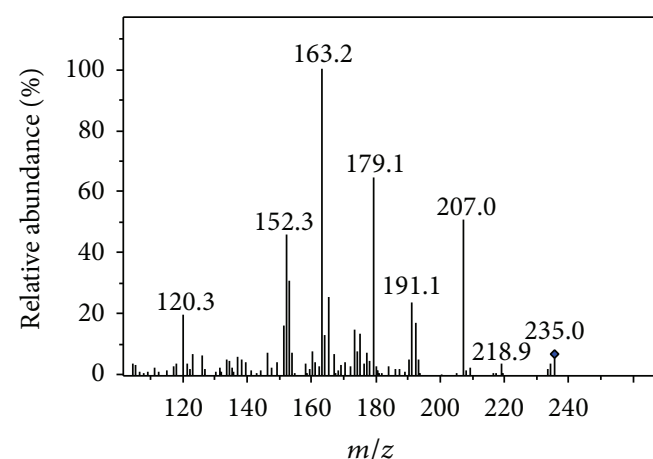

(a)

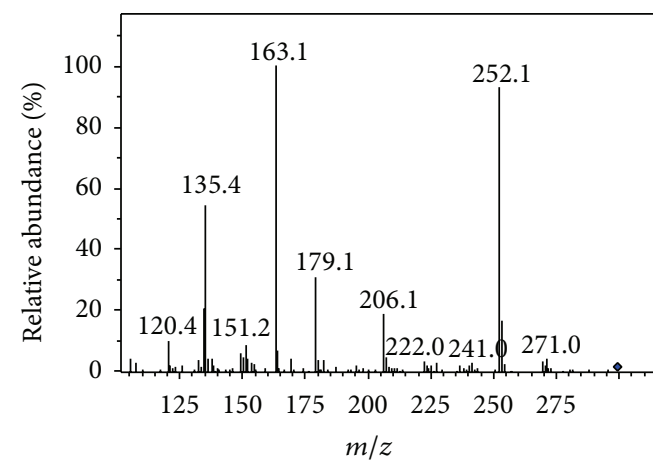

(c)

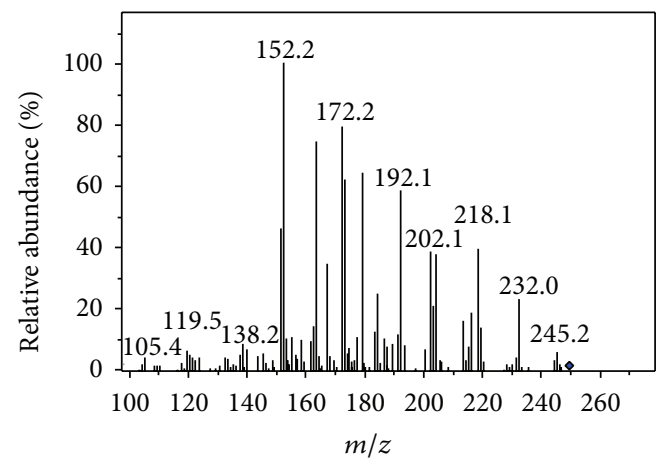

(e)

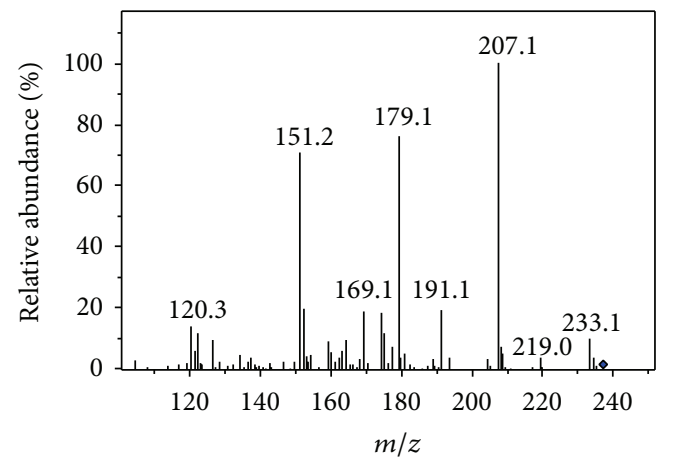

(g)

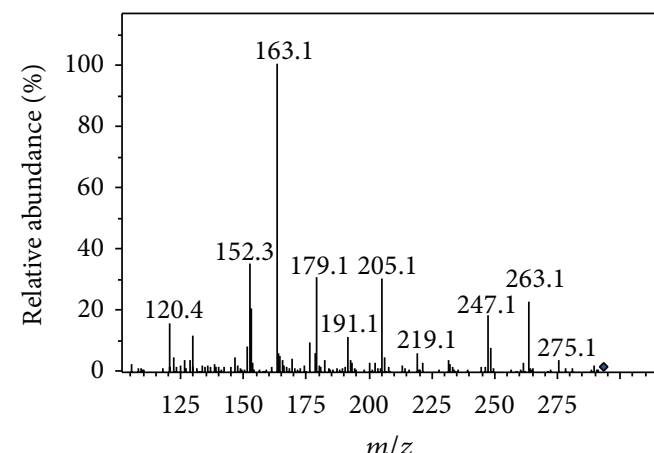

(b)

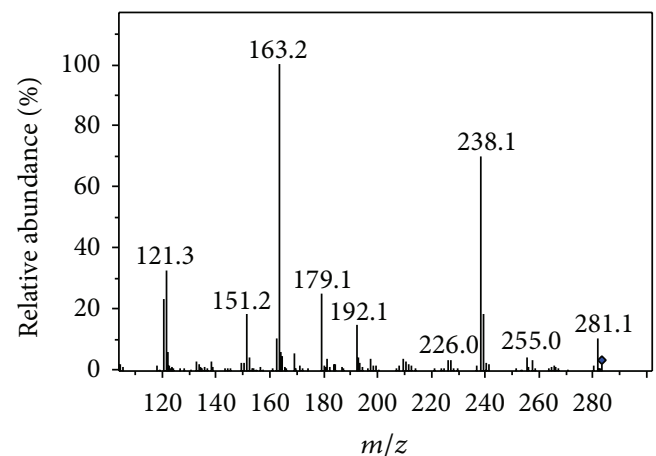

(d)

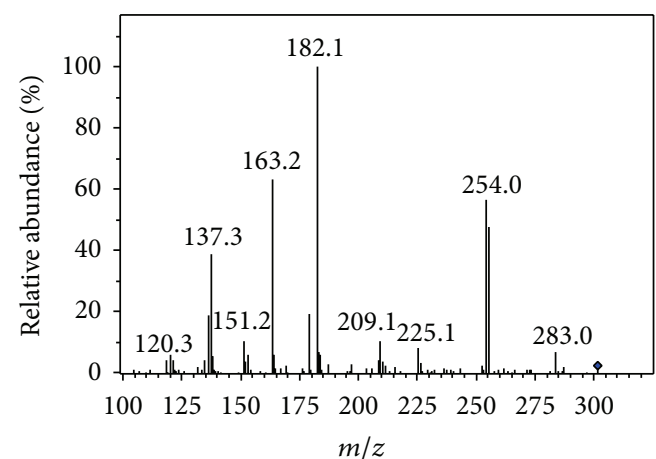

(f)

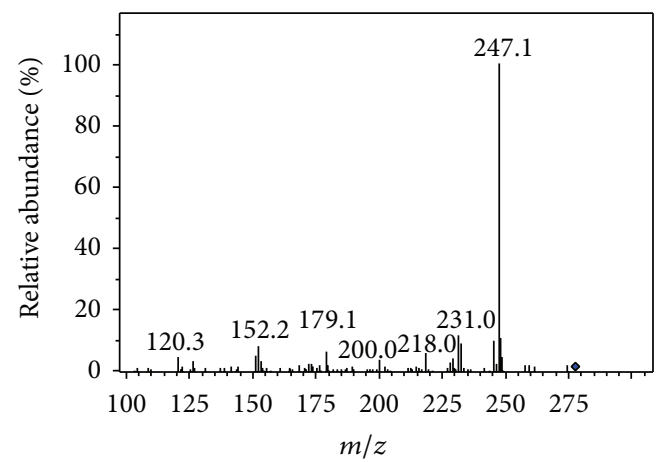

(h)

FIGURE 3: MS/MS spectra obtained from the $[\mathrm{M}-\mathrm{H}]^{-}$ion fragmentation of selected hydrazones: (a) propionaldehyde; (b) heptanaldehyde; (c) o-, m-, and p-tolualdehydes; (d) benzaldehyde; (e) crotonaldehyde; (f) salicylaldehyde; (g) acetone; and (h) cyclohexanone. 


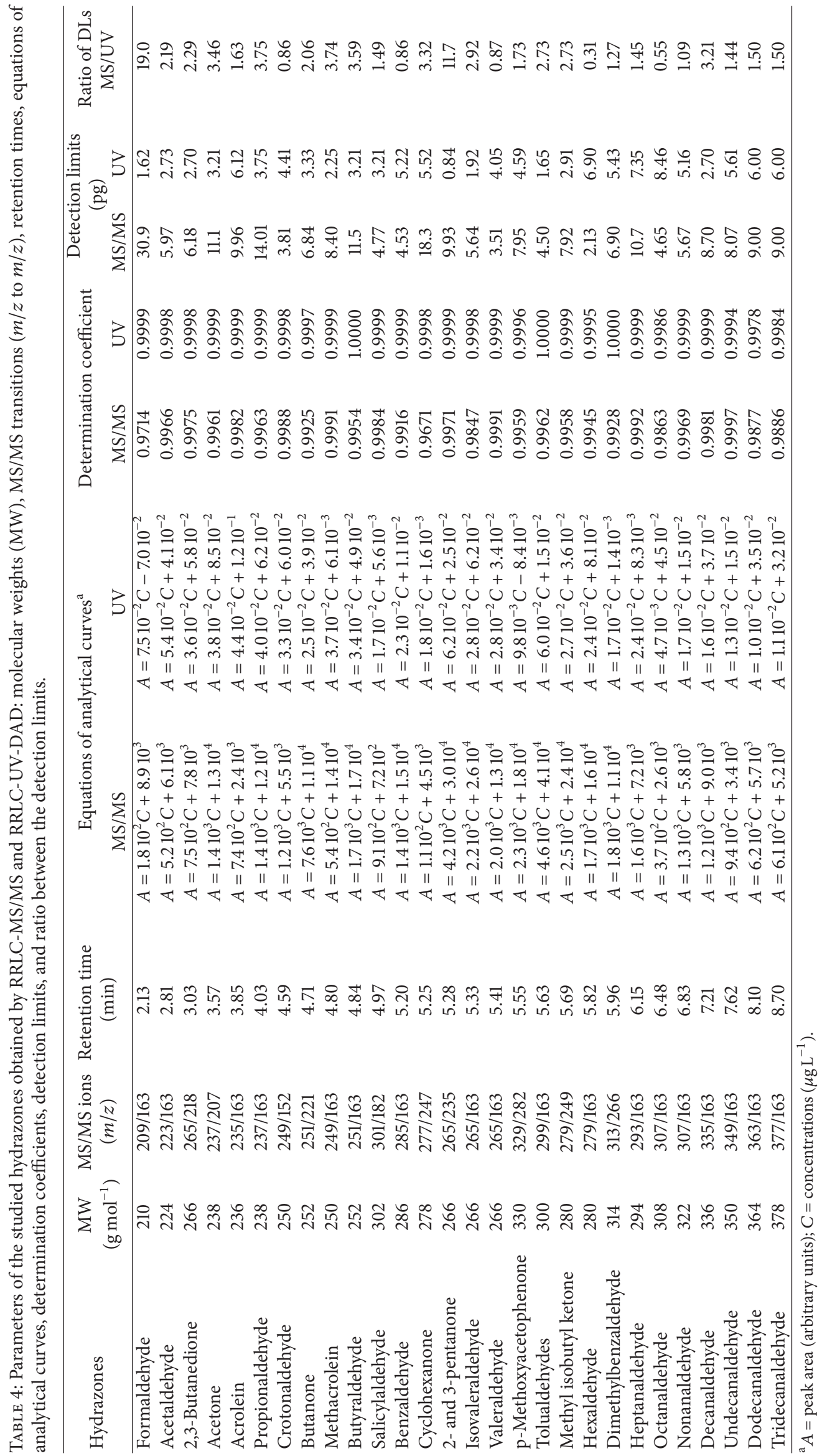




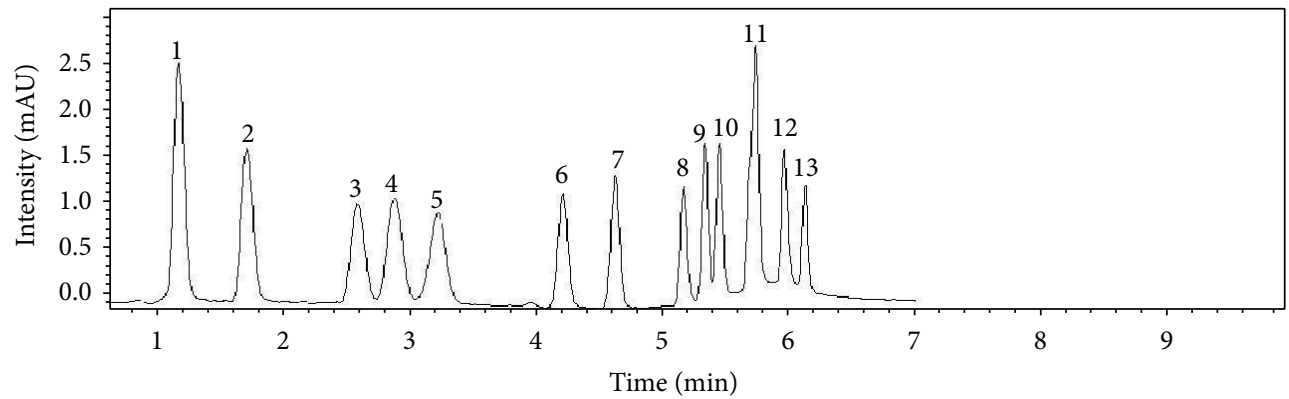

(a)

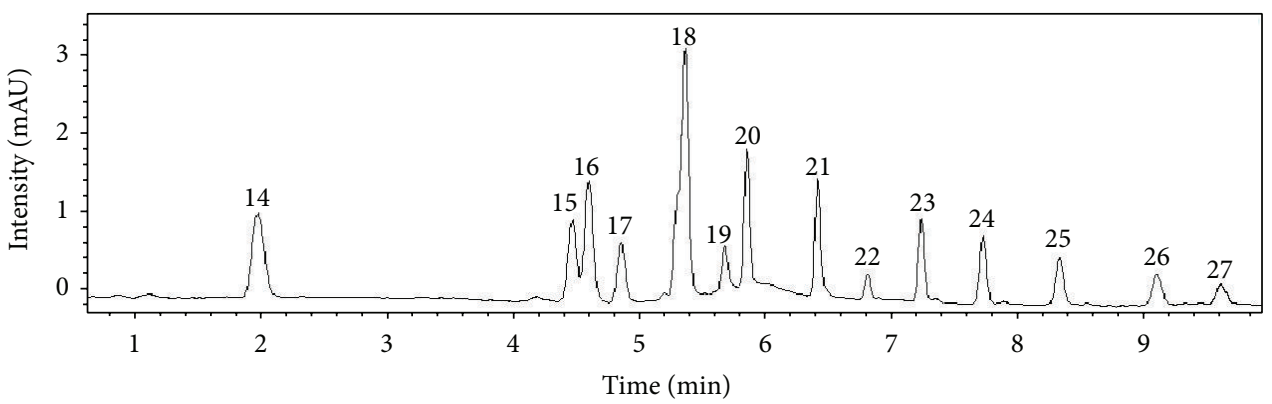

(b)

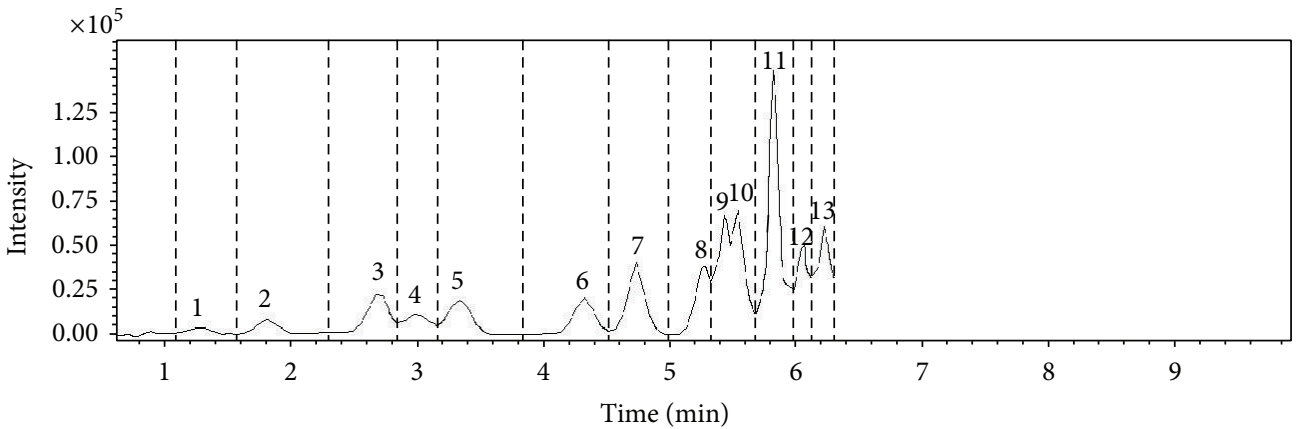

(c)

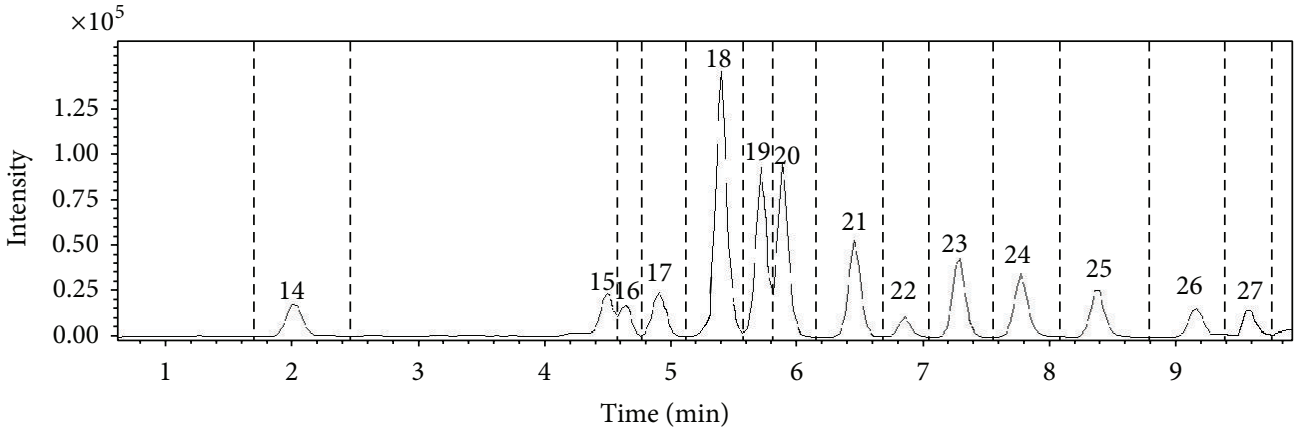

(d)

FIgURE 4: Chromatograms of a mixture of ((a) and (c)) CC-DNPH derivatives from T011/IP-6A Supelco and ((b) and (d)) hydrazones of selected CC synthesized $\left(200 \mu \mathrm{g} \mathrm{L}^{-1}\right)$ by RRLC-UV-DAD method ((a) and (b)) and by RRLC-APCI-MS/MS method ((c) and (d)) (peak identification: hydrazones of 1: formaldehyde; 2: acetaldehyde; 3: acetone; 4: acrolein; 5: propionaldehyde; 6: crotonaldehyde; 7: butyraldehyde; 8: benzaldehyde; 9: isovaleraldehyde; 10: valeraldehyde; 11: o-, $\mathrm{m}-$, and p-tolualdehyde; 12: hexaldehyde; 13: 2,5dimethylbenzaldehyde; 14: 2,3-butanedione; 15: butanone; 16: methacrolein; 17: salicylaldehyde; 18: cyclohexanone, 3-pentanone, and 2-pentanone; 19: p-methoxyacetophenone; 20: methyl isobutyl ketone; 21: heptanaldehyde; 22: octylaldehyde; 23: nonanaldehyde; 24: decanaldehyde; 25: undecanaldehyde; 26: dodecanaldehyde; 27: tridecanaldehyde). 
an intense fragment of $m / z 182$ and a low abundance of fragment of $m / z 179$ [25] as observed in the MS/MS spectrum of salicylaldehyde-DNPH (Figure 3(f)) that shows an ion of $m / z 182$ as main fragment ion.

Aldehydes and ketones hydrazones can be differentiated by their different fragmentation pathways. Ketones showed low or no formation of the fragment of $m / z 163$ and an ion of $\mathrm{m} / z 152$ of high relative abundance, as shown in the MS/MS spectra of acetone and cyclohexanone (Figures $3(\mathrm{~g})$ and $3(\mathrm{~h})$, resp.). Ketones also showed a highly abundant fragment of [M-H-30] $]^{-}$, as shown in the spectra of acetone $(\mathrm{m} / z 207)$ and cyclohexanone $(m / z 247)$ (Figures $3(\mathrm{~g})$ and $3(\mathrm{~h})$, resp.). This ion was also found in the mass spectra of aldehydes, but with a relative low abundance.

Although the fragmentation pathways evaluation represents an important tool to achieve the structure elucidation of unknown CC-hydrazones, the most abundant and specific ions are fundamental for quantitative analysis using single reaction monitoring (SRM) techniques when the predominant transitions gave rise to the most intense signals, improving the sensitivity for quantitative measurements.

3.3. Comparison of RRLC-APCI-MS/MS Method with RRLCUV-DAD Method for Quantification of Carbonyl-DNPH Derivatives. Table 3 shows the MS/MS transitions chosen for the MRM method. In general, the most predominant transitions were used. The regression plots and some parameters of the analytical curves obtained by RRLC-APCI-MS/MS and RRLC-UV-DAD method with detection at $360 \mathrm{~nm}$ as described in our previous work [10] are also shown and compared in Table 4 . The chromatograms of the two groups of CC, 15 CC-DNPH derivatives from T011/IP-6A Supelco and 16 hydrazones of selected $\mathrm{CC}$ synthesized, obtained by RRLC-UV-DAD and RRLC-APCI-MS/MS method are shown in Figure 4.

The analytical curves showed different linear ranges for each hydrazone and detection technique. In general, the RRLC-APCI-MS method showed a linear range between 1 and $200 \mu \mathrm{g} \mathrm{L}^{-1}$ and the RRLC-UV-DAD method between 2 and $500 \mu \mathrm{g} \mathrm{L} \mathrm{L}^{-1}$.

The sensitivity of a method is evaluated by the regression slope, but in this case the values were not comparable due to high magnitudes of signals obtained by RRLC-APCI-MS/MS that was five orders higher $\left(1.1 \times 10^{2}\right.$ to $\left.4.6 \times 10^{3}\right)$ than RRLC-UV-DAD method $\left(4.7 \times 10^{-3}\right.$ to $\left.7.5 \times 10^{-2}\right)$. Both methods showed determination coefficients closer to the unity indicating a good adherence to a linear model, but the RRLC-UV-DAD method showed values closer to 1 ( 0.9978 to $1.0000)$ than RRLC-APCI-MS method (0.9671 to 0.9997).

The detection limits of the hydrazones obtained by RRLCAPCI-MS/MS varied between 2.13 and $30.9 \mathrm{pg}$ and were approximately two or three times higher than those of RRLCUV-DAD method, which were in the range of 0.84 to $8.46 \mathrm{pg}$. A closer evaluation of the ratios between these DLs shows that the most discrepant differences occur for formaldehyde and 2- and 3-pentanones.

However, despite the higher sensitivity of UV detection, the major advantage of $\mathrm{MS}^{2}$ detection relies on method selectivity because this technique allows the identification of other CC-hydrazones, besides the studied ones here, considering their fragmentation.

Our results indicate that the application of RRLC-APCIMS/MS and RRLC-UV-DAD method for determination of carbonyl compounds in environmental samples after derivatization to hydrazones may lead to comparable results for quantitation considering DL and QL. For example, considering typical processing conditions for the analysis of air samples (volume of sampled air $60 \mathrm{~L}$ and extract dilution, $5 \mathrm{~mL}$ ) the detection limits correspond to values between 0.23 and $0.02 \mu \mathrm{g} \mathrm{m}^{-3}$ using UV detection and to values between 0.86 and $0.06 \mu \mathrm{g} \mathrm{m}^{-3}$ using the SRM-MS detection.

Moreover, the detection techniques can also be used as complementary ones, once apparently the UV detection allows better detection limits and a wide linearity to be achieved and the mass spectrometry detection $\left(\mathrm{MS}^{2}\right)$ confers a higher selectivity to the analytical method, besides being an excellent tool for identifying other hydrazones and for confirmation of those detected and quantified with UV.

\section{Conclusions}

In our work specifically, RRLC-UV-DAD was more sensitive for detection of hydrazones than RRLC-APCI-MS/MS, which, on the other hand, offers several advantages such as the positive identification of CC in samples by examining the fragmentation pattern of hydrazones, even without analytical standards. The detection limit $\left(0.71-10.3 \mu \mathrm{g} \mathrm{L}^{-1}\right)$ of this technique is slightly worse than that of RRLC-UV-DAD method, but it could also allow the quantification of carbonyl in air samples, for example. The rapid resolution liquid chromatography system allowed significant improvements of resolution, throughput, and low detection limits. The simultaneous evaluation of hydrazones using both methods APCI-MS/MS and UV-DAD raised up a suitable analytical methodology for the analysis of CC in complex environmental mixtures.

\section{Conflict of Interests}

The authors declare that there is no conflict of interests regarding the publication of this paper.

\section{Acknowledgments}

The authors would like to thank CAPES, CNPq, FAPERJ, and PETROBRAS for financial support and fellowships. Annibal D. Pereira Netto thanks CNPq for an individual research grant.

\section{References}

[1] X. Pang and X. Lee, "Temporal variations of atmospheric carbonyls in urban ambient air and street canyons of a Mountainous city in Southwest China," Atmospheric Environment, vol. 44, pp. 2098-2106, 2010.

[2] J. A. Huang, Y. L. Feng, J. M. Fu, and G. Y. Sheng, "A method of detecting carbonyl compounds in tree leaves in China," 
Environmental Science and Pollution Research, vol. 17, pp. 11291136, 2010.

[3] K. Fujioka and T. Shibamoto, "Determination of toxic carbonyl compounds in cigarette smoke," Environmental Toxicology, vol. 21, no. 1, pp. 47-54, 2006.

[4] X. Pang and A. C. Lewis, "Carbonyl compounds in gas and particle phases of mainstream cigarette smoke," Science of the Total Environment, vol. 409, no. 23, pp. 5000-5009, 2011.

[5] M. C. Rodrigues, L. L. N. Guarieiro, M. P. Cardoso, L. S. Carvalho, G. O. da Rocha, and J. B. de Andrade, "Acetaldehyde and formaldehyde concentrations from sites impacted by heavy-duty diesel vehicles and their correlation with the fuel composition: diesel and diesel/biodiesel blends," Fuel, vol. 92, no. 1, pp. 258-263, 2012.

[6] M. V. A. S. de Andrade, H. L. C. Pinheiro, P. A. P. Pereira, and J. B. de Andrade, "Compostos carbonílicos atmosféricos: fontes, reatividade, níveis de contaminação e efeitos toxicológicos," Química Nova, vol. 25, no. 6B, pp. 1117-1131, 2002.

[7] M. Skybova, J. Lenicek, A. Rychtecka et al., "Determination of volatile organic compounds in the atmosphere and their influence on ozone formation," Fresenius Environmental Bulletin, vol. 15, no. 12, pp. 1616-1623, 2006.

[8] International Agency for Research on Cancer, Monographs on the Evaluation of Carcinogenic Risks to Humans, vol. 88, 2006.

[9] International Agency for Research on Cancer, Working Group on the Evaluation of Carcinogenic Risks to Humans: Wood dust and Formaldehyde, 1995.

[10] S. M. Ochs, M. Fasciotti, R. P. Barreto et al., "Optimization and comparison of HPLC and RRLC conditions for the analysis of carbonyl-DNPH derivatives," Talanta, vol. 81, no. 1-2, pp. 521529, 2010.

[11] A. B. de Carvalho, M. Kato, M. M. Rezende, P. A. D. P. Pereira, and J. B. de Andrade, "Determination of Carbonyl compounds in the atmosphere of Charcoal plants by HPLC and UV detection," Journal of Separation Science, vol. 31, no. 10, pp. 1686-1693, 2008.

[12] Y. G. Chi, Y. L. Feng, S. Wen et al., "Determination of carbonyl compounds in the atmosphere by DNPH derivatization and LCESI-MS/MS detection," Talanta, vol. 72, no. 2, pp. 539-545, 2007.

[13] K. Takeda, S. Katoh, N. Nakatani, and H. Sakugawa, "Rapid and highly sensitive determination of low-molecular-weight carbonyl compounds in drinking water and natural water by preconcentration HPLC with 2,4-dinitrophenylhydrazine," Analytical Sciences, vol. 22, no. 12, pp. 1509-1514, 2006.

[14] Method for the Determination of Formaldehyde in Ambient Air Using Adsorvent Cartridge Followed by High Performance Liquid Chromatography (HPLC), Compendium Method TO11A, US Environmental Protection Agency, Office of Research and Development, Research Triangle Park, NC, USA, 1999.

[15] A. Sakuragawa, T. Yoneno, K. Inoue, and T. Okutani, "Trace analysis of carbonyl compounds by liquid chromatographymass spectrometry after collection as 2,4-dinitrophenylhydrazine derivatives," Journal of Chromatography A, vol. 844, no. 1-2, pp. 403-408, 1999.

[16] J. R. Mazzeo, U. D. Neue, M. Kele, and R. S. Plumb, "Advancing LC performance with smaller particles and higher pressure," Analytical Chemistry, vol. 77, no. 23, pp. 460A-467A, 2005.

[17] S. D. M. Ochs, F. C. Albuquerque, M. C. G. P. Massa, and A. D. Pereira Netto, "Evaluation of C1-C13 carbonyl compounds by RRLC-UV in the atmosphere of Niterói City, Brazil," Atmospheric Environment, vol. 45, no. 29, pp. 5183-5190, 2011.
[18] S. M. Ochs, L. O. Grotz, L. S. Factorine, M. R. Rodrigues, and A. D. P. Netto, "Occupational exposure to formaldehyde in an institute of morphology in Brazil: a comparison of area and personal sampling," Environmental Science and Pollution Research, vol. 19, no. 7, pp. 2813-2819, 2012.

[19] S. Kolliker, M. Oehme, and C. Dye, "Structure elucidation of 2,4-dinitrophenylhydrazone derivatives of carbonyl compounds in ambient air by HPLC/MS and multiple MS/MS using atmospheric chemical ionization in the negative ion mode," Analytical Chemistry, vol. 70, no. 9, pp. 1979-1985, 1998.

[20] S. Klliker, M. Oehme, and L. Merz, "Unusual MS ${ }^{n}$ fragmentation patterns of 2,4-dinitrophenylhydrazine and its propanone derivative," Rapid Communications in Mass Spectrometry, vol. 15, no. 22, pp. 2117-2126, 2001.

[21] E. Grosjean, P. G. Green, and D. Grosjean, "Liquid chromatography analysis of carbonyl (2,4-dinitrophenyl) hydrazones with detection by diode array ultraviolet spectroscopy and by atmospheric pressure negative chemical ionization mass spectrometry," Analytical Chemistry, vol. 71, no. 9, pp. 1851-1861, 1999.

[22] G. Zurek, H. Luftmann, and U. Karst, "HPLC-APCI-MS with calibration based on stable isotope-labelled internal standards for the quantification of carbonyls in air samples," Analyst, vol. 124, no. 9, pp. 1291-1295, 1999.

[23] V. van den Bergh, I. Vanhees, R. de Boer, F. Compernolle, and C. Vinckier, "Identification of the oxidation products of the reaction between $\alpha$-pinene and hydroxyl radicals by gas and high-performance liquid chromatography with mass spectrometric detection," Journal of Chromatography A, vol. 896, no. 1-2, pp. 135-148, 2000.

[24] V. Van den Bergh, H. Coeckelberghs, I. Vanhees, R. De Boer, F. Compernolle, and C. Vinckier, "HPLC-MS determination of the oxidation products of the reaction between $\alpha$ - and $\beta$-pinene and $\mathrm{OH}$ radicals," Analytical and Bioanalytical Chemistry, vol. 372, no. 5-6, pp. 630-638, 2002.

[25] R. Andreoli, P. Manini, M. Corradi, A. Mutti, and W. M. A. Niessen, "Determination of patterns of biologically relevant aldehydes in exhaled breath condensate of healthy subjects by liquid chromatography/atmospheric chemical ionization tandem mass spectrometry," Rapid Communications in Mass Spectrometry, vol. 17, no. 7, pp. 637-645, 2003.

[26] C. E. Baños and M. Silva, "Liquid chromatography-tandem mass spectrometry for the determination of low-molecular mass aldehydes in human urine," Journal of Chromatography B, vol. 878, no. 7-8, pp. 653-658, 2014.

[27] C. Zweiner, T. Glauner, and F. H. Frimmel, "Method optimization for the measurement of carbonyl compounds in disinfected water by DNPH derivatization and LC-ESI/MS/MS," Analytical and Bioanalytical Chemistry, vol. 372, no. 5-6, pp. 615-621, 1997.

[28] S. D. Richardson, T. V. Caughran, T. Poiger, Y. Guo, and F. Gene Crumley, "Application of DNPH derivatization with LC/MS to the identification of polar carbonyl disinfection by-products in drinking water," Ozone: Science \& Engineering, vol. 22, no. 6, pp. 653-675, 2000.

[29] S. M. van Leeuwen, L. Hendriksen, and U. Karst, "Determination of aldehydes and ketones using derivatization with 2,4-dinitrophenylhydrazine and liquid chromatography-atmospheric pressure photoionization-mass spectrometry," Journal of Chromatography A, vol. 1058, no. 1-2, pp. 107-112, 2004.

[30] D. B. Robb, T. R. Covey, and A. P. Bruins, "Atmospheric pressure photoionization: An ionization method for liquid 
chromatography - Mass spectrometry," Analytical Chemistry, vol. 72, no. 15, pp. 3653-3659, 2000.

[31] S. Brombacher, M. Oehme, and J. A. Beukes, "HPLC combined with multiple mass spectrometry $\left(\mathrm{MS}^{n}\right)$ : an alternative for the structure elucidation of compounds and artefacts found in smog chamber samples," Journal of Environmental Monitoring, vol. 3, no. 3, pp. 311-316, 2001.

[32] M. Uebori and K. Imamura, "Analysis of aliphatic and aromatic carbonyl compounds in ambient air by LC/MS/MS," Analytical Sciences, vol. 20, no. 10, pp. 1459-1462, 2004.

[33] F. Gosetti, U. Chiuminatto, E. Mazzucco et al., "Simultaneous determination of thirteen polycyclic aromatic hydrocarbons and twelve aldehydes in cooked food by an automated online solid phase extraction ultra high performance liquid chromatography tandem mass spectrometry," Journal of Chromatography A, vol. 1218, no. 37, pp. 6308-6318, 2011.

[34] E. Grosjean and D. Grosjean, "Carbonyl collection efficiency of the DNPH-coated $\mathrm{C}_{18}$ cartridge in dry air and in humid air," Environmental Science and Technology, vol. 30, no. 3, pp. 859863, 1996.

[35] G. R. Ramos and M. C. G. Alvarez-Coque, Quimiometria, Editorial Sintesis, Madrid, Spain, 2001. 

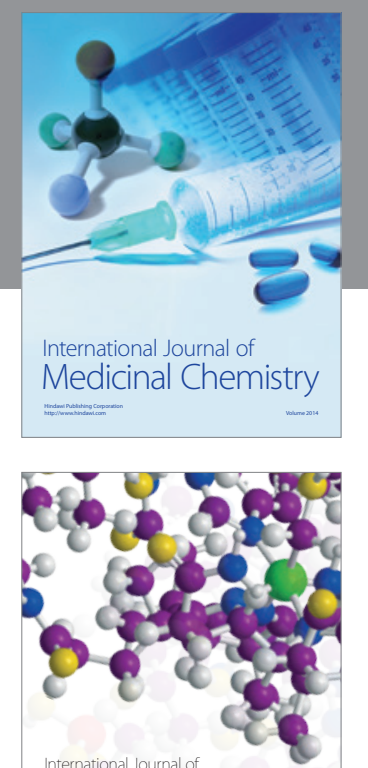

\section{Carbohydrate} Chemistry

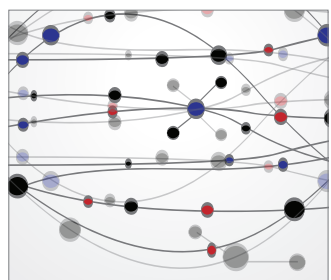

The Scientific World Journal
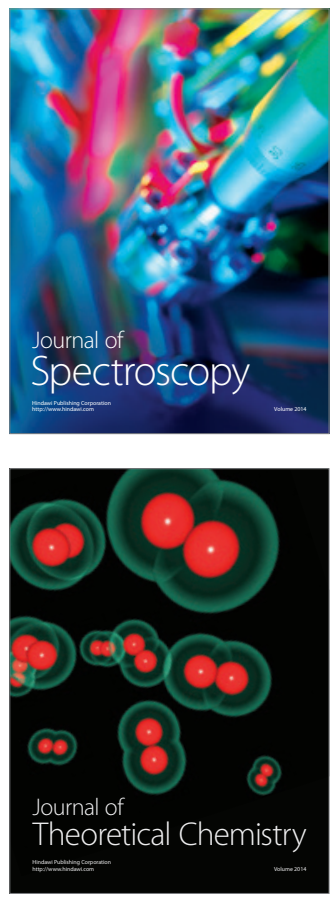
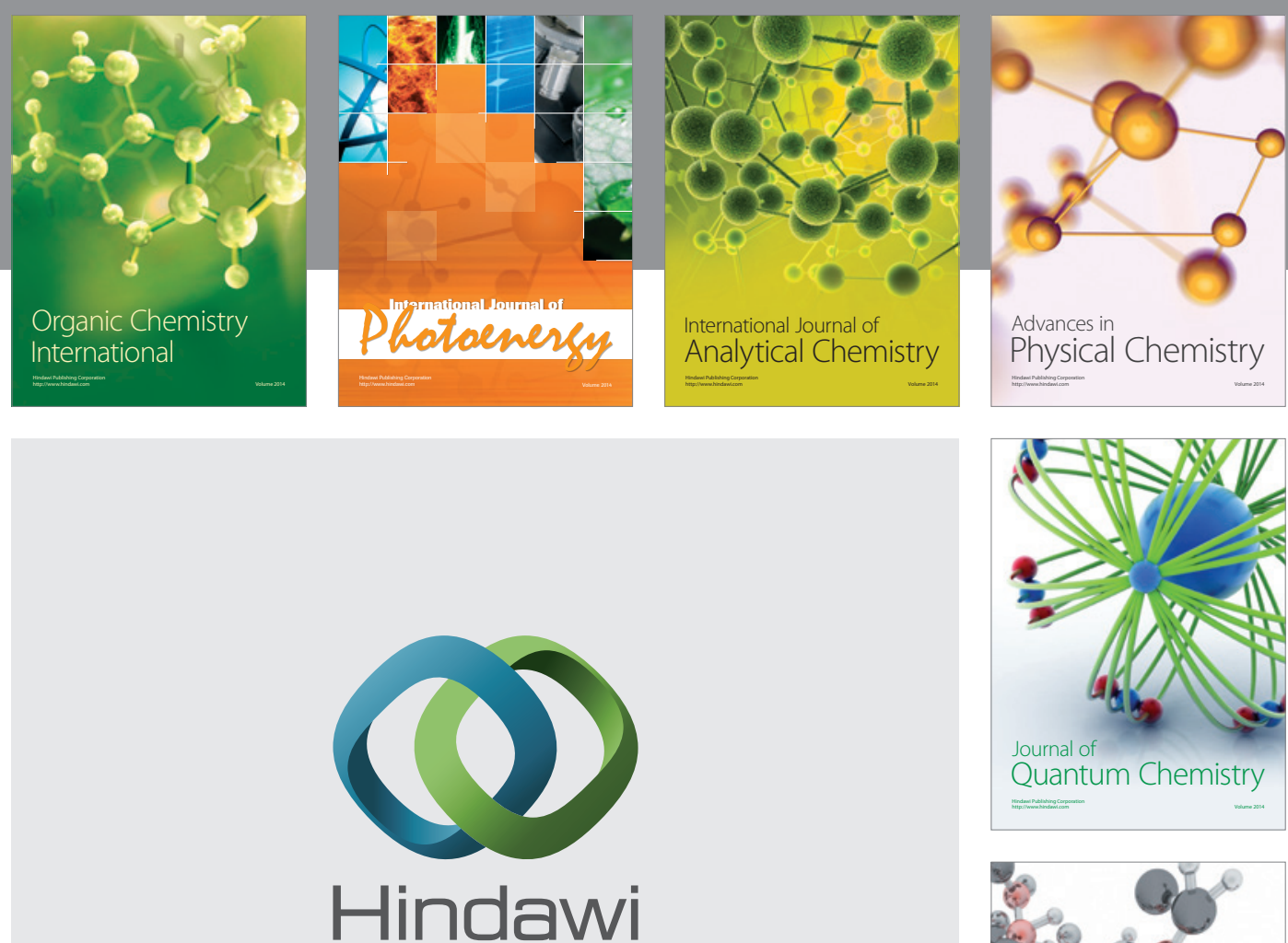

Submit your manuscripts at

http://www.hindawi.com

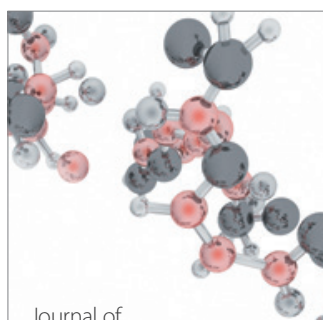

Analytical Methods

in Chemistry

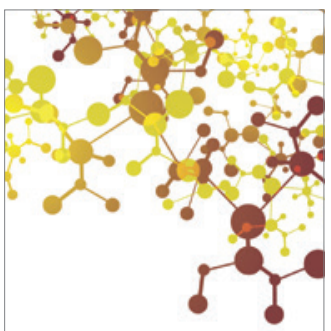

Journal of

Applied Chemistry

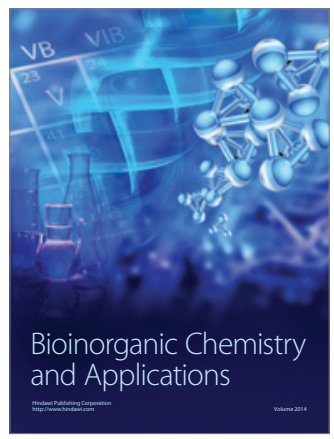

Inorganic Chemistry
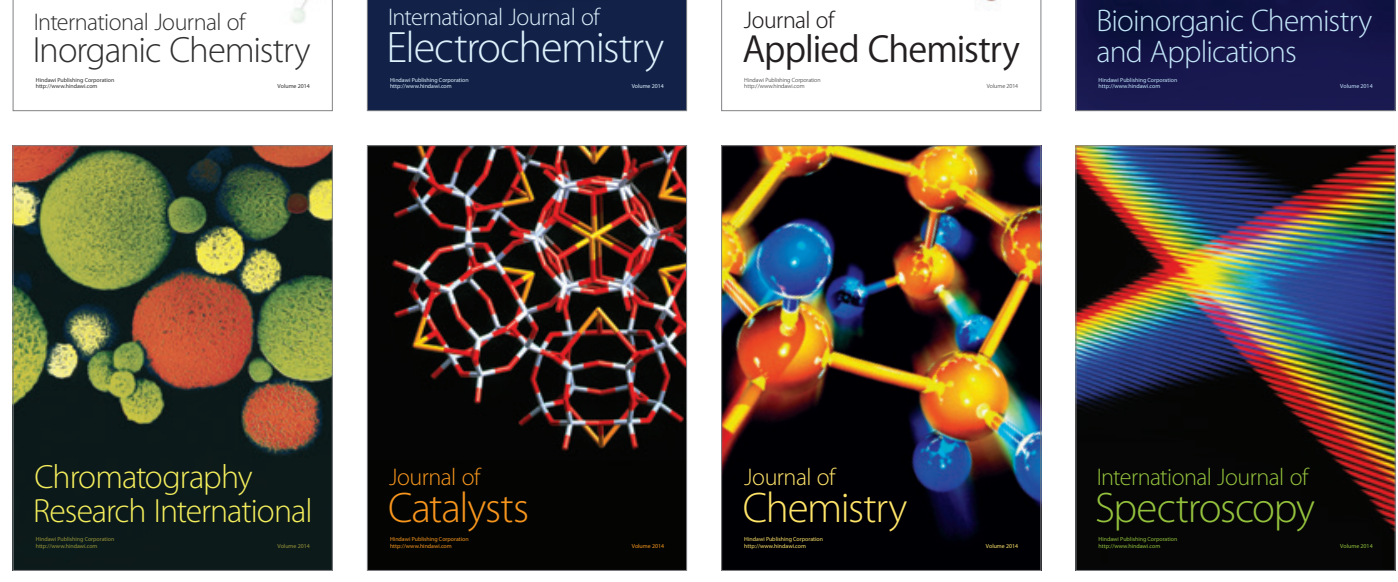